Project ID: 70135, 86814, 05SCPML68 (Proposal number from Los Alamos Lab Collaborator)

Project Title: Colloid-Facilitated Transport of Radionuclides through the Vadose Zone

Grant Number: FG07-99ER62882, FG07-02ER63496 (collaborative project)

Publication Date: May 31, 2006

Lead Principal Investigator:

Markus Flury, Department of Crop and Soil Sciences, Washington State University, Pullman, WA 99164, Phone: 509-335-1719, Email: flury@mail.wsu.edu.

\title{
Co-Investigators:
}

James B. Harsh, Department of Crop and Soil Sciences, Washington State University, Pullman, WA 99164, Phone: 509-335-3650, Email: harsh@mail.wsu.edu.

John M. Zachara, Environmental Molecular Science Laboratory, Pacific Northwest National Laboratories, Richland, WA 99352, Phone: 509-376-3254, Email: john.zachara@pnl.gov.

John F. McCarthy, Department of Geology, University of Tennessee, Knoxville, TN 37996, Phone: 865-974-8039, Fax: 865-974-8086, Email: jmccart1@utk.edu.

Peter C. Lichtner, Geoanalysis-Earth and Environmental Sciences, Los Alamos National Laboratory, Los Alamos, NM 87545, Phone: 505-667-3420, Fax: 505-665-8737, Email:

lichtner@lanl.gov.

\section{Research Objectives:}

This project seeks to improve the basic understanding of the role of colloids in facilitating the transport of contaminants in the vadose zone. We focus on three major thrusts: (1) thermodynamic stability and mobility of colloids formed by reactions of sediments with highly alkaline tank waste solutions, (2) colloid-contaminant interactions, and (3) in-situ colloid mobilization and colloidfacilitated contaminant transport occurring in both contaminated and uncontaminated Hanford sediments. The specific objectives that will be addressed are:

1. Determine the lability and thermodynamic stability of colloidal materials, which form after reacting Hanford sediments with simulated Hanford Tank Waste.

2. Determine the potential of Hanford sediments for in-situ mobilization of colloids for different types of sediments and different leaching scenarios.

3. Characterize the interactions between initially-formed colloids, their dissolution/alteration products, and native colloidal particles with contaminants in batch experiments under various ionic strength and $\mathrm{pH}$ conditions.

4. Evaluate colloid-facilitated radionuclide transport through sediments under different degrees of water saturation in packed and undisturbed sediment columns. 
5. Implement colloid-facilitated contaminant transport mechanisms and thermodynamic stability constants into a reactive chemical transport model, and verify model simulations with experimental transport data.

Results of this project will help to understand the fundamental mechanisms of Cs transport under the leaking Hanford tanks, and thus contribute to the long-term clean-up strategies at the Hanford site.

\section{Research Progress and Implications:}

This report summarizes work after 3.8 years of a 3-year project (plus no-cost extension year).

In the no-cost extension period, we have completed our experimental work and have written and revised technical manuscripts. We have completed the experiments on mineral transformations when Hanford sediments are reacted with caustic Hanford tank waste. The major findings (cancrinite, sodalite, zeolite A and allophane form when Hanford tank waste leaks into subsurface sediments, determination of intraparticle Cs diffusion rates) have been submitted and published in technical journals. We have also completed the work on silicate mineral resistance to alkaline Hanford waste solutions. Silicate minerals exposed to highly-alkaline solutions from high-level radioactive waste leaks had different dissolution resistance. Selective dissolution of the minerals will influence the solution chemistry and the precipitation of new solid phases, which can alter the sorption and transport of contaminants present in the wastes. The mineral resistance to caustic solutions was predicted based on solution compositions and solubility product constants. The predictions were compared to experimental observations obtained from a Hanford fine sand and several model minerals (muscovite, biotite, smectite, illite, vermiculite, and chlorite) reacted with simulated tank wastes (STW). Theoretical predictions and experimental observations indicate that quartz was the most labile mineral in the alkaline solutions. Amphibole, pyroxene, and chlorite were the most stable phases. The relative resistance of the minerals in the alkaline solutions increased in the following order: quartz $<$ kaolinite $<$ smectite $<$ illite $<$ vermiculite $<$ mica $<$ feldspars $<$ chlorite, amphiboles, pyroxenes.

The large undisturbed sediments cores, which were collected from the ERDF pit, are currently irrigated at low flow rates representative for Hanford recharge, and are being monitored for colloid mobilization. Cores are continuously weighed and water content and water potentials are monitored. The experimental setup has been refined and the irrigation experiment is underway now for six months. Outflow from the core is not expected until next year.

We have completed the work on in-situ colloid mobilization under transient flow conditions using columns repacked with Hanford sediments. Five series of unsaturated column experiments were performed with initial infiltration rates of $0.018,0.036,0.072,0.144$ and $0.288 \mathrm{~cm} / \mathrm{min}$. The cumulative amount of colloids released was linearly proportional to the column water content established after steady-state flow rates were achieved. The colloid release rate coefficient increased nearly linearly with the increase of water content. The results suggest that under the low flow rates at Hanford, colloid transport should not be significant unless the water flow occurs in preferential flow channels or is funneled by textural layering. However, experiments from undisturbed sediments are needed to verify these preliminary findings. 
We continued the work on precipitation and adsorption of europium on smectite and calcite. Smectite and calcite were mixed with Eu solutions for up to one year in either capped or open centrifuge tubes. When an amount of Eu that was equivalent to twice the CEC of smectite was added, about $50 \%$ of the added Eu was adsorbed in $\mathrm{pH}$ range 3-5.5, and the adsorption did not vary significantly $(<5 \%)$ with $\mathrm{pH}$ in this range, implying that smectite was nearly saturated with Eu and that the affinity of Eu to smectite was strong. Europium precipitated as short-range ordered and nano-sized $\mathrm{Eu}(\mathrm{OH}) 3$ particles on smectite when $\mathrm{pH}$ was raised above 6 , but adsorption of Eu on smectite did occur at high $\mathrm{pH}(6-10)$ as evidenced by the expansion of the $\mathrm{d}(001)$ space of smectite from $1.2 \mathrm{~nm}$ to $1.5 \mathrm{~nm}$. Ligand EDTA inhibited the precipitation of $\mathrm{Eu}(\mathrm{OH}) 3$ on smectite and reduced the adsorption nearly two-thirds in $\mathrm{pH}$ range 4-10. Presence of EDTA and humic acid completely inhibited the formation of the europium carbonate phases. Thermodynamic modeling with softwares MEDUSA and HYDRA agreed well with the observations with $\mathrm{Eu}(\mathrm{OH}) 3$ but did not agree with the carbonate phases, presumably due to poor thermodynamic constants. Under the natural $\mathrm{pH}$ condition (around 8) of the Hanford sediment, it is likely that Eu forms carbonate and hydroxide precipitates. The precipitation can decrease the mobility of radioactive contaminants in sediment.

At the University of Tennessee, we continued the studies on understanding the impacts of transient flow regimes and horizontal sediment layering on colloid transport. The results showed that more in-situ colloids were released during the transient flow than during the steady state flow. The number of short-term hydrological pulses proved more vital than total irrigation volume or persistence time length for increasing the amount of mobilized in-situ colloids. We measured this flow-pattern-induced colloid release using a so-called "The whole is less than sum of its parts" rule. An implicit mechanism underlying this rule is transient perturbation of flow, which can render jumps/non-equilibrium of physical and chemical potentials at the solid-liquid interfaces and lead to colloid release. The experiments also demonstrate that increase of ionic strength diminished the effect derived from the above rule. At an irrigation rate equal to $5 \%$ of the saturated hydraulic conductivity (Ks), transient multi-pulse flow in $2 \mathrm{mM} \mathrm{NaNO} 3$ was equivalent to a fifty-fold reduction of solution ionic strength (from $100 \mathrm{mM}$ to $2 \mathrm{mM}$ ) in a single pulse flow in terms of their positive effects on in-situ colloid mobilization. These tests highlight that transient flow is critical for colloid mobilization, and that long-term assessment of colloid release should consider the transient rainfall/irrigation pattern.

We also performed experiments to examine the finger-channeled transport of montmorillonite (Mt) colloids and its dependence on layering-structure of porous media. The measured results indicate that the injected Mt particles exhibited preferential transport along the flow-fingers of water. The cumulative mass of the transported colloids varied among the ten outlets located at the bottom of the flow cell, and the transport was impacted by the presence of layered structure. The breakthrough curves verified that the presence of fine sand layer in coarse sand lowered the concentrations of Mt in the effluents, and the effect was enhanced as the texture of the inserted layer became fine. This resulted from accumulation of the Mt colloids in the fine sand layer. We thus expect that subsequent infiltration will cause remobilization and preferential transport of the colloids residing in the fine layer. The fine sand layer obviously acted as a secondary redistributor of the colloids as was observed for the water. These preliminary results provide significant insights into the processes of water distribution and colloid mobilization in the layered sediments at Hanford, and suggest a necessity of systematic study on the effects of soil layering on colloid transport and mobilization. 


\section{Planned Activities:}

The last phase of the project will be used to revise technical manuscripts and write the final project report. The major future activities and their time lines are listed below:

Completion and revision of technical manuscripts: June, 2006 to September, 2006.

Final report write-up:

June, 2006 to September, 2006.

\section{Information Access:}

A WEB site is maintained for reporting and dissemination of research results. The WEB site can be accessed through the home page of Markus Flury at http://akasha.wsu.edu. Several scientific manuscripts of the work done so far have been published or submitted for publication and others are in preparation. The published manuscripts are all available in electronic form as PDF files at http://akasha.wsu.edu. The following manuscripts have been published or submitted during the reporting period:

Mashal, K., J.B. Harsh, and M. Flury, Clay mineralogical transformations over time in Hanford sediments reacted with simulated tank waste, Soil Sci. Soc. Am. J., 69, 531-538, 2005.

Czigany, S., M. Flury, J.B. Harsh, B.C. Williams, and J.M. Shira, Suitability of fiberglass wicks to sample colloids from vadose zone pore water, Vadose Zone J., 4, 175-183, 2005.

Czigany, S., M. Flury, and J.B. Harsh, Colloid stability in vadose zone Hanford sediments, Environ. Sci. Technol., 39, 1506-1512, 2005.

Chen, G., M. Flury, J.B. Harsh, and P.C. Lichtner, Colloid-facilitated transport of cesium in variably-saturated Hanford sediments, Environ. Sci. Technol., 39, 3435-3442, 2005.

Chen, G., and M. Flury, Retention of mineral colloids in unsaturated porous media as related to their surface properties, Colloids Surf. Physicochem. Eng. Aspects, 256, 207-216, 2005.

Mashal, K., J.B. Harsh, M. Flury, and A.R. Felmy, Analysis of precipitates from reactions of hyperalkaline solutions with soluble silica, Appl. Geochem., 20 1357-1367, 2005.

Mon, J., Y. Deng, M. Flury, and J.B. Harsh, Cesium incorporation and desorption in feldspathoids, zeolite, and allophane, Micropor. Mesopor. Mat., 86, 277-287, 2006.

Deng, Y., J.B. Harsh, M.Flury, J.Young, and J. S. Boyle, Mineral formation during simulated leaks of Hanford waste tanks, Appl. Geochem., (in press), 2006.

Shira, J.M., B.C. Williams, M. Flury, S. Czigany, and M. Tuller, Sampling silica and ferrihydrite colloids with fiberglass wicks under unsaturated flow conditions, J. Environ. Qual., (in press), 2006.

Deng, Y., M. Flury, and J.B. Harsh, Cancrinite and sodalite formation in the presence Cs, K, Mg, $\mathrm{Ca}$, or $\mathrm{Sr}$ in Hanford tank waste simulants, Appl. Geochem., (revised and resubmitted), 2006. 
Deng, Y., H. Zhao, K. Mashal, J. B. Harsh, M. Flury, and J. S. Boyle. Resistance of silicate minerals to alkaline waste simulants. Vadose Zone J., (submitted), 2006. 